\title{
AS IMPLICAÇÕES DO SISTEMA DE PATENTES E A EVOLUÇÃO TECNOLÓGICA: A BIOTECNOLOGIA COMO INSTRUMENTO IMPACTANTE NA NORMATIZAÇÃO DA PROPRIEDADE INTELECTUAL
}

\author{
THE PATENT SYSTEM IMPLICATIONS AND TECHNOLOGICAL \\ DEVELOPMENT: BIOTECHNOLOGY AS IMPACTFUL INSTRUMENT IN \\ STANDARDIZATION OF INTELLECTUAL PROPERTY
}

\author{
${ }^{1}$ Marco Antônio Pontes Aires \\ ${ }^{2}$ Isabel Christine Silva De Gregori
}

\section{RESUMO}

O presente ensaio propõe-se a apresentar as implicações que envolvem o sistema de patentes e sua evolução tecnológica a partir da perspectiva do desvelamento da biotecnologia e dos possíveis impactos refletidos no instituto da Propriedade Intelectual. O escopo do estudo também destina-se analisar as "intenções econômicas" do Acordo Sobre Aspectos dos Direitos de Propriedade Intelectual Relacionados ao Comércio (TRIPS), objetivos da Convenção sobre Diversidade Biológica (CDB), e o modelo hegemônico dos países desenvolvidos. A solução remonta ao reconhecimento da falência do regime internacional de propriedade intelectual costurado em bases econômicas e a implementação de um modelo compatível com a CDB.

Palavras-chave: Biotecnologia, Propriedade Intelectual, Convenção sobre Diversidade Biológica, Acordo TRIPS, Modelo Hegemônico.

\begin{abstract}
This paper proposes to present the implications involving the patent system and its technological evolution from the unveiling of the perspective of biotechnology and possible impacts reflected in the Institute of Intellectual Property. The scope of the study is intended to analyze the "economic intentions" of the Agreement on Aspects of Intellectual Property Rights Related to Trade, objectives of the Convention on Biological Diversity, and the hegemonic model of developed countries. The solution goes back to the recognition the failure of the international intellectual property regime on an economic basis and the implementation of a model compatible with the CDB.
\end{abstract}

Keywords: Biotechnology, Intellectual Property, Convention on Biological Diversity, Agreement TRIPS, Hegemonic Model.

\footnotetext{
${ }^{1}$ Mestrando em Direito pela Universidade Federal de Santa Maria - UFSM, Rio Grande do Sul, (Brasil). Email: marco80aires@gmail.com

${ }^{2}$ Doutora em Desenvolvimento Regional pela Universidade de Santa Cruz do Sul - UNISC, Rio Grande do Sul, (Brasil). Professora do Curso de Direito da Universidade Federal de Santa Maria - UFSM. Chefe do Departamento de Direito da UFSM.
} 


\section{INTRODUÇÃO}

$\mathrm{O}$ advento da tecnologia produziu muitas mudanças nas ações e relações humanas. $\mathrm{O}$ sistema de patentes, por meio do crescimento da tecnologia, expandiu de maneira rápida e controversa. A todo o momento, ocorrem transformações e evoluções tecnológicas com dinamismo e facilidade, em qualquer área.

A biotecnologia permite que seres vivos sejam manipulados no todo ou em parte. Essa manipulação faz com que sejam produzidos bens e serviços, alcançando as tecnologias de vários níveis. Sua utilização passa pela produção de alimentos e bebidas até a manipulação genética. Nesse sentido, os olhares de todos da sociedade ficam voltados a esses desdobramentos tecnológicos.

Dessa forma, hodiernamente, percebem-se os mais diversos aspectos das mudanças ocasionadas a partir de uma revolução tecnológica, que vem modificando profundamente a forma como vivemos em sociedade. Com isso, é preciso compreender o que significam a biotecnologia e o sistema de patentes, assim como, o impacto ocasionado na propriedade intelectual e na sociedade em geral pela utilização desse instrumento.

Contudo, como cerne para uma possível solução para esse entrave encontra-se a busca pela quebra de um paradigma hegemônico pautado em um modelo econômico. Sistema desenvolvido principalmente pelos países que detêm o avanço tecnológico e a soberania no patenteamento.

Partindo dessa perspectiva, define-se como problema de pesquisa: Quais as possibilidades do rompimento do modelo hegemônico pautado na economia e da utilização da biotecnologia pelos países latino-americanos em conformidade com a proteção da diversidade biológica? Diante disso, apresenta-se de extrema importância o presente assunto, visto que, este ensaio esclarecerá dúvidas sobre as implicações do sistema de patentes e a evolução tecnológica com a biotecnologia como instrumento impactante na normatização da propriedade intelectual.

Quanto à metodologia, revela expor que o presente está consolidado no método de abordagem dialético, pois sendo o direito uma ciência histórica, objetiva-se que a contraposição de ideias entre diferentes autores, possibilite uma síntese crítica, que não objetiva - de forma alguma - esgotar o tema, mas lançar novos questionamentos e possibilidades sobre o mesmo. O método de procedimento monográfico e comparativo, a partir do qual foram selecionados livros, revistas e artigos científicos nacionais e 
internacionais, bem como se faz um embate entre o Acordo TRIPS e a CDB. Procurou-se realizar levantamentos a partir de dados bibliográficos, com objetivo de alcançar a solução da pesquisa.

Para tanto, em um primeiro momento, abordar-se-á acerca das preliminares da biotecnologia, buscando elucidar todos os aspectos referentes a esse instrumento. Assim, como os benefícios que as modificações genéticas e biológicas podem trazer a sociedade e algumas peculiaridades sobre o tema. Em seguida, o sistema de propriedade intelectual seu desenvolvimento e impacto com a revolução tecnológica, desvelando-se o sistema de patenteamento e a normatização existente no Brasil.

Logo, expõem-se os instrumentos que visam tutelar a propriedade intelectual e o sistema de patentes, com a análise das intenções econômicas do Acordo Sobre Aspectos dos Direitos de Propriedade Intelectual Relacionados ao Comércio (TRIPS), os objetivos da Convenção sobre Diversidade Biológica (CDB) e o modelo hegemônico dos países desenvolvidos. Por fim, responder-se-á o problema de pesquisa desse estudo, de modo a contribuir para um melhor esclarecimento e entendimento da relevância do tema abordado.

\section{PRELIMINARES ACERCA DA BIOTECNOLOGIA}

O interesse pela biotecnologia e sua implicação no sistema de patentes deve-se as potencialidades inerentes à sua aplicação. De modo inicial, faz-se necessário conceituar, de acordo com o Art. 2, parte 2, da Convenção de Diversidade Biológica, a biotecnologia como “toda aplicação tecnológica que utiliza sistemas biológicos e organismos vivos ou seus derivados para a criação ou modificação de produtos ou processos para usos específicos". Ou ainda, pode ser definida, como sendo "a manipulação de seres vivos ou partes destes para produzir bens e serviços, englobando tecnologias de diversos níveis, desde a fermentação, utilizada na produção de alimentos e bebidas até a manipulação genética" (FIGUEIREDO; PENTEADO; MEDEIROS, 2006, p. 32).

Cientistas, investidores privados, indústrias e principalmente lideranças mundiais voltam seus olhares ao tema. A importância da implementação de políticas públicas para contribuir no desenvolvimento das organizações industriais nos países em desenvolvimento (do Sul), ensejam a necessidade de entendimento das apostas que vem sendo realizadas em âmbito mundial e seus desdobramentos tecnológicos (REIS, 2009, p. 360-362). 
Foram, por conseguinte, devido à evolução tecnológica, junto às atividades legais e administrativas que garantiram a sustentação da pesquisa nesse campo, resultado dos interesses econômicos atraídos pela certeza de lucro, que levaram a evolução e ao crescimento do grau de dependência social que constituiu ao redor da biotecnologia. A biotecnologia incorporou um imenso valor aos genes existentes no ambiente, ao favorecer a intercessão no campo mais importante da vida, ou seja, no DNA, outorgando a intervenção, transformação e inclusive o aponderamento da vida pelo sistema de propriedade intelectual (MOREIRA et al., 2003, p. 1).

Nesse sentido, surge um questionamento a respeito do patenteamento desses seres, visto que o resultado das pesquisas envolvem seres vivos e o sistema de patentes que alcançou uma importância estratégica. Este fato desencadeou um movimento de mudança do sistema de patentes, de modo que, converteu sua lógica, onde antes se baseava na não concessão de vantagens sobre os seres vivos na valorização da invenção, negando aquilo que fosse simples descoberta (MOREIRA et al., 2003, p. 2).

O sistema de patentes, inclusive no âmbito dos medicamentos, permite que empresas se apropriem dos conhecimentos das populações tradicionais e comunidades locais, não conferindo nenhuma proteção a tais saberes. A desconsideração das características e dos saberes culturais desses povos ficam evidentes com as intenções da Organização Mundial de Propriedade Intelectual (OMPI) (SANTILLI, 2004, p. 353).

\footnotetext{
Os conhecimentos tradicionais são produzidos e gerados de forma coletiva, a partir de ampla troca e circulação de ideias e informações, e transmitidos oralmente, de uma geração à outra. $\mathrm{O}$ sistema de patentes protege as inovações individuais (ou, ainda que as inovações sejam coletivas, seus autores/inventores podem ser individualmente identificados), promovendo uma fragmentação dos conhecimentos (SANTILLI, 2004, p. 353).
}

Nesse mesmo sentido, Santos e Meneses (2010, p. 58) alertam sobre as ameaças que a intervenção dos crescentes avanços tecnológicos traz às populações tradicionais. Conhecimentos dos camponeses e dos povos indígenas que poderiam contribuir para a preservação da biodiversidade são mitigados pela ciência moderna.

Ainda, constata-se que, por meio da biotecnologia, uma quantidade enorme de vacinas está sendo produzidas e aceitas pela sociedade. Todos os Organismos Geneticamente Modificados (OGMs) tendem a ser utilizados para o bem ou para o mal, dependendo da direção que seguir (GARCIA, 2003, p. 7). 
Percebe-se que é necessário um exame detalhado da importância dos benefícios que as modificações genéticas e biológicas podem trazer a sociedade. Uma vez, que o saber científico é muito relevante para todos, resta evidenciar se os benefícios dos novos produtos da ciência, não afetam de maneira prejudicial os povos. Há que se pesar a sua utilização.

Dessa forma, o sistema de patentes vem padecendo mudanças no contexto internacional. O setor de ciência e tecnologia recebeu maiores investimentos com a evolução da biotecnologia e com isso, o surgimento da necessidade de instrumentos que assegurem a exequibilidade dos investimentos feitos (MOREIRA et al., 2003, p. 1-2).

Todavia, a pressão internacional é forte, no que se refere à concordância do patenteamento do todo ou parte de seres vivos. Nota-se que o Sistema de Propriedade Intelectual vive um momento de divisão, pleiteando-se entre as novas necessidades da indústria biotecnológica, que roga pela concessão ampla de patentes para esse setor, e a necessidade de privilegiar invenções e não meras descobertas. Outrossim, é comprovado um profundo dilema ético, a respeito de uma nova onda de dominação do homem sobre o próprio homem (MOREIRA et al., 2003, p. 2).

Importante que se faça menção ao monopólio conferido pelas patentes, pois apenas 4\% dos gastos com pesquisa e desenvolvimento, conferem aos países em desenvolvimento. Os recursos mundiais utilizados para esse fim contemplam $84 \%$ dos dez países mais industrializados, sendo que destes, 94\% "são titulares das patentes outorgadas no âmbito mundial e recebem 91\% dos royalties transfronteiras por licenciamento de tecnologia" (CORREA, 2007, p. 20).

A Propriedade Intelectual é um meio de proteger a criação humana, por meio da implementação de direito de apropriação ao homem sobre suas criações, obras e produções do intelecto, talento e engenho. Seu principal objetivo é o de garantir aos inventores por qualquer produção do intelecto o direito de ganhar recompensa por sua criação, por período de tempo determinado (MOREIRA et al., 2003, p. 10).

Sabe-se que a biotecnologia não é algo novo, pois um aprofundamento do conhecimento científico sobre os processos biológicos vem ocorrendo desde a metade do século XX. Com isso, transcorreu-se um avanço no entendimento da ciência com relação a diversos fenômenos, desencadeando a expansão de novas tecnologias, com o poder de afetar fortemente a ciência e dessa forma, a sociedade (REIS, 2009, p. 361).

Observa-se ainda, que a biotecnologia não é definida pelos seus produtos, mas sim pelas tecnologias usadas para se produzir tais produtos (PAUGH; LAFRANCE, 1997). Existe 
uma nítida diferença entre atividades que englobam tradicionais e modernas biotecnologias. A biotecnologia tradicional é composta por um conjunto de técnicas vastamente disseminadas, que utilizam seres vivos achados na natureza ou aperfeiçoados pelo homem para exercer determinada função produtiva, como técnicas de isolamento, a seleção e cruzamentos genéticos naturais entre espécies sexualmente compatíveis (SILVEIRA, 2002).

No entanto, a biotecnologia moderna surgiu em meados dos anos setenta, a partir de descobertas científicas no ramo da engenharia genética. Conforme Carvalho (1996), a biotecnologia moderna envolve o campo da engenharia genética (que transfere genes de um organismo para outro) e a fusão celular (formação de uma única célula por fusão de duas diferentes).

É na biotecnologia moderna que surge a penicilina e a invenção dos antibióticos. A forma sistemática que a biotecnologia se organiza, demonstra a necessidade de um aumento de produção de fármacos, bem como uma amplitude de desenvolvimento das bioindústrias com a utilização de técnicas de Engenharia Genética. Nesse sentido, a revolução biotecnológica se fez presente por meio de empresas que se interessaram no financiamento da prática de patenteamento no setor da biotecnologia. A visão de uma lucratividade futura aliada a busca por soluções para os problemas da humanidade, são a contrapartida dos altos custos das pesquisas com a aplicação da biotecnologia. Entretanto, apesar do otimismo dos pesquisadores, a utilização desta tecnologia pode ser arriscada, por não haver uma previsão dos seus efeitos em longo prazo na natureza (OLIVEIRA, 1997).

Nesse contexto, o direito teve a necessidade de se adaptar ao desenvolvimento tecnológico. Para tanto, o advento da biotecnologia, aliado com as questões de patenteamento, restaram evidenciadas no Sistema de Propriedade Intelectual. Assunto abordado no próximo capítulo.

\section{O SISTEMA DE PROPRIEDADE INTELECTUAL}

A elaboração de uma gama de leis para garantir alguns direitos ao homem, seu bemestar e sua dignidade, fez-se necessário para que o direito, após o advento das mudanças provocadas na sociedade com o desenvolvimento da biotecnologia, fosse atualizado. Foram, essenciais à normatização dos organismos geneticamente modificados, assim como a "determinação de limite ético e social para o patenteamento dos resultados da pesquisa e desenvolvimento tecnológicos baseados na Biotecnologia” (MOREIRA et al., 2003, p. 7). 
No Brasil, por exemplo, a Constituição Federal buscou proteger o meio ambiente, elevando a um direito de todos, sem bloquear o crescimento tecnológico-científico e com isso o desenvolvimento econômico, quando estabeleceu dentre seus dispositivos a preservação da diversidade e a plenitude do patrimônio genético do país, juntamente com uma fiscalização dos entes aplicados à pesquisa e manipulação dos materiais genéticos. Ainda, em seu artigo $218, \S 2^{\circ}$, aduz que a pesquisa tecnológica é importante no avanço do sistema de produção nacional e regional (MOREIRA et al., 2003, p. 7).

As peculiaridades no que se refere à biotecnologia estão dispostas em uma regulamentação infraconstitucional, assim, a Lei $\mathrm{n}^{\mathrm{o}}$. 11.105 de 2005 dispõe sobre a Biossegurança de Organismos Geneticamente Modificados. Da mesma forma, a Lei $\mathrm{n}^{\circ}$. 9.279 de 1996 regulamenta produtos e processos resultantes da biotecnologia e a propriedade industrial, e a Medida Provisória $n^{\circ}$. 2.186-16 de 2001, o acesso e uso do patrimônio genético (MOREIRA et al., 2003, p. 7-8).

Um sistema de patentes em expansão e flexível possibilita o patenteamento de OGMs, desde que apresentem os requisitos de patenteabilidade. A permissão está prevista no artigo 18, III da Lei de Propriedade Industrial. Questões externas e internas exerceram pressão para que a legislação brasileira fosse modificada. Alguns membros da sociedade acreditam, em relação às pressões internas, que o "uso abusivo das Patentes Biotecnológicas seria proveitoso para o país, promovendo-se assim o efetivo patenteamento pelo órgão competente". Enquanto outros, em referência às pressões externas, remontam a questão internacional na elaboração das normas sobre propriedade industrial. Essa pressão tem os Estados Unidos como cerne e principal interessado no patenteamento dos seres vivos e pela assinatura do Acordo Sobre Aspectos dos Direitos de Propriedade Intelectual Relacionados ao Comércio (TRIPS), no âmbito da Organização Mundial do Comércio (OMC), ratificado pelo Decreto $\mathrm{n}^{\circ} 1.355$ em 1994 (MOREIRA et al., 2003, p. 8).

Para Vandana Shiva (2001), todo o processo de expansão das patentes equivale às descobertas. Um resultado do padrão de reducionismo da biologia, atribuindo valor econômico à natureza. Conforme o homem considera a biotecnologia como sua criação, sua propriedade agrega valor para a venda e, simultaneamente, lucratividade.

Dessa forma, a aplicação dos requisitos de patenteamento previstos no artigo $8^{\circ}$ da Lei no 9.279 de 1996, ou seja, "a invenção que atenda aos requisitos de novidade, atividade inventiva e aplicação industrial", não ficam adstritos a processos efetivamente novos. É 
permitida uma interpretação ampliada, pois podem ser modificados os conhecimentos preexistentes, sem agregar-lhes novidade (VIEIRA, 2012, p. 102).

Como visto, o monopólio torna-se forte, na medida em que a extensão dos direitos de patentes a descobertas não contribui com a possibilidade inovação. Nesse contexto, o que existe é uma limitação no requisito da novidade, pois garante o monopólio do mercado.

\begin{abstract}
A concessão de patentes reduz a eficiência estática, porque não se tem um acesso ótimo aos recursos, o que diminui o bem-estar da sociedade, ao conferir exclusividade ao titular da patente. Em troca, a patente deveria promover a eficiência dinâmica identificada pela apresentação de produtos novos e de melhor qualidade. A aplicação de requisitos de patenteabilidade, no entanto, que permitam o patenteamento de produtos ou processos de duvidosa novidade e atividade inventiva, mitigando a caracterização da invenção, não promovem a eficiência dinâmica porque se o alcance da patente é amplo, os concorrentes são dissuadidos de inovar no campo por ela coberto, uma vez que poderiam ser julgados como infratores (CORREA, 2005, p.51).
\end{abstract}

Portanto, valendo-se dessa análise, quando existe o compartilhamento da ideia de adoção de um sistema de propriedade intelectual com uma amplitude de apropriação de biotecnologias que descobrem substâncias da natureza, o bem-estar das pessoas e a promoção da inovação restam prejudicados. A eficiência estática e a eficiência dinâmica ficam limitadas na função de garantir a proteção de produtos comercializáveis.

Os países em desenvolvimento não veem com bons olhos a ampliação de patentes biotecnológicas. Isso porque a diversidade, tanto de culturas dos povos tradicionais, quanto de espécies, encontra-se localizada em grande parte nesses países. A incapacidade científica e tecnológica avançada limita a produção de biotecnologias. Nem a instalação de empresas industriais multinacionais com matriz local reduz esse distanciamento tecnológico (VIEIRA, 2012, p. 105).

Nesse sentido, Vinícius Garcia Vieira (2012, p. 105), apresenta as práticas de etnobioprospecção. Uma técnica entendida como a investigação de empresas multinacionais dos conhecimentos dos povos indígenas, "sobre os usos que fazem da fauna e flora em suas tradições culturais, de forma a identificar substâncias que possam ter propriedades terapêuticas ou cosméticas para posterior extração e comercialização privada”.

Observa-se que a concessão ampliada de patentes permite que a extração realizada por meio da retirada das substâncias in loco nos países com maior diversidade, sejam patenteadas e comercializadas por outros países. Nota-se que a biotecnologia aplicada com 
efetividade na extração, a eleva à qualificação de mercadoria, ficando evidente o caráter econômico da ciência tecnológica.

As controversas inerentes à comercialização da biotecnologia e a necessidade de proteção da biodiversidade colocam em cheque a normatização patentearia. As intenções econômicas do Acordo Sobre Aspectos dos Direitos de Propriedade Intelectual Relacionados ao Comércio (TRIPS) e os objetivos da Convenção sobre Diversidade Biológica (CDB) andam em sentidos opostos. Por isso, a necessidade de se analisar a seguir as divergências e interações desses instrumentos normativos, bem como, a (des)construção do poder hegemônico dos países desenvolvidos.

\section{AS DIVERGÊNCIAS ENTRE O ACORDO TRIPS VERSUS CDB E (DES)CONSTRUÇÃO DO PODER HEGEMÔNICO}

A existência de dois instrumentos legais internacionais para a normatização do sistema de patentes traz à tona suas divergências. De um lado a Convenção sobre Diversidade Biológica (CDB) representa uma luta histórica contra a dependência dos países do Sul Social (em desenvolvimento), em relação aos países do Norte Social (desenvolvidos) calcada na exploração econômica, enquanto que do outro lado, "as regras do acordo TRIPS visam a manter o status quo das relações Norte-Sul e dar continuidade ao grau de exclusão daqueles países da repartição das riquezas do mundo" (MAIA FILHO, 2010, p. 119).

Conforme acima, o Acordo TRIPS confronta com o instrumento legal assinado e ratificado pelo Brasil no Decreto Legislativo nº 2 de 1994, a Convenção sobre Diversidade Biológica (CDB):

[...] os países têm poder soberano sobre seus recursos biológicos e que deve haver uma repartição de benefícios justa e equitativa para o que vier a ser desenvolvido utilizando recursos do patrimônio genético nacional e saberes de comunidades tradicionais existentes no país. A Medida Provisória no 2.186-16/01, acima citada, vem regulamentar a alínea " $\mathrm{j}$ ” do artigo $8^{\circ}$ da Convenção, sendo que essa Medida Provisória seria posterior e constantemente regulamentada pelo Conselho de Gestão do Patrimônio Genético (CGEN) (MOREIRA et al., 2003, p. 8-9).

Diante disso, realizou-se em 2001 a quarta reunião Ministerial da Organização Mundial do Comércio (OMC), em Doha no Catar. Na ocasião, organizou-se uma nova rodada de negociações chamada de rodada de Doha, na qual foi elaborada a Declaração de Doha. Nessa declaração houve a discussão sobre os temas a serem tratados, que culminou na 
realização, por parte do Conselho para Assuntos Relacionados a Aspectos da Propriedade Intelectual (Conselho TRIPS), de uma comparação entre a CDB e o acordo TRIPS (MAIA FILHO, 2010, p. 76-77).

Com isso, constatou-se um dos problemas que se apresentam na relação entre estes dois instrumentos internacionais. A existência ou não, de "uma incompatibilidade entre seus dispositivos, e o que deveria ser feito para garantir que ambos fossem aplicados em consonância de maneira a se apoiarem mutuamente" (MAIA FILHO, 2010, p. 77).

Observa-se três grupos distintos no âmbito da Organização Mundial do Comércio (OMC), o grupo africano, países desenvolvidos e países em desenvolvimento. O primeiro relata uma divergência por existir dentro do Acordo TRIPS a possibilidade de apropriação do patrimônio genético pelos entes privados e a não exigência de consentimento prévio dos países que detêm os recursos genéticos, nem a repartição dos benefícios conseguidos por meio desses recursos. Enquanto que a CDB dispõe sobre a soberania dos países sobre seus recursos e a necessidade de consentimento prévio para a apropriação dos mesmos. O grupo africano ainda defende, que invenções partindo do conhecimento dos povos tradicionais e qualquer tipo de vida, no todo ou em parte, não sejam passíveis de patenteamento (MAIA FILHO, 2010, p. 77-78).

O segundo grupo, dos países desenvolvidos, acredita que não existe incompatibilidade entre os dois instrumentos. E fundamenta com a inexistência de conflitos em casos concretos com relação a CDB e o Acordo TRIPS. Já o terceiro grupo, dos países em desenvolvimento, no qual se enquadram o Brasil, países latino-americanos, China e Índia, por exemplo, veem a necessidade "de uma ação internacional orientada para a aplicação conjunta de seus preceitos de maneira complementar". Acreditam que os instrumentos normativos devem correr na mesma direção e sustentam uma alteração nos objetivos do Acordo TRIPS para que se tenha efetivação das garantias propostas (MAIA FILHO, 2010, p. 79).

Uma das principais críticas dos países do sul social em relação ao acordo TRIPS faz menção ao problema da biopirataria. De acordo com Juliana Santilli (2004, p. 346), mesmo não havendo uma definição jurídica, biopirataria pode ser estabelecida como a "atividade que envolve o acesso aos recursos genéticos de um determinado país ou aos conhecimentos tradicionais associados a tais recursos genéticos” (ou a ambos). Revela expor que essa técnica invasiva está em discordância com o que rege a $\mathrm{CDB}$, que é a proteção aos conhecimentos tradicionais, a soberania do país de origem em seus recursos genéticos e repartição dos 
benefícios, mediante o acesso adequado a esses recursos e a adequação da transferência de tecnologias (DE GREGORI, 2013, p. 152).

Portanto, o Acordo TRIPS permite que se reclamem os direitos de propriedade intelectual de recursos genéticos que estão sob a soberania de outros países, inclusive por entes privados. Um exemplo conhecido é o caso da planta ayahuasca, usada como medicamento pelos povos indígenas da Amazônia que foi patenteada nos Estados Unidos e "é usada comercialmente por agentes privados estrangeiros, sem qualquer repartição de benefícios ou respeito pelos conhecimentos tradicionais ou direitos soberanos sobre a planta" (MAIA FILHO, 2010, p. 79).

De acordo com Santos e Meneses (2010, p.32-37), nos territórios dos povos tradicionais, aplica-se a divisão apropriação/violência, em que os conhecimentos coloniais, desaparecem, não são relevantes nas maneiras de conhecimentos. A apropriação envolve a adequação, acomodação e incorporação, ao passo que, a violência imposta implica na destruição cultural, física, humana e material.

A profunda dualidade que envolve a hegemonia dá conta de um monopólio instituído pelas grandes corporações que contribuem para criar complexos científico-militares ou industriais. Os requisitos de qualidade foram trocados pela quantidade e produtividade. $\mathrm{O}$ crescimento da hegemonia Norte/Sul e o pensamento abissal são abarcados na desigualdade e na incidência de desordem. Os países em desenvolvimento e as classes dominantes se beneficiam das desigualdades regionais e mundiais. A lei do mais forte prepondera (SANTOS; MENESES, 2010, p. 38-39).

Ainda, nesse entendimento Jerônimo Siqueira Tybusch (2011, p. 299), argumenta que "a racionalidade dominante não permite pensar fora das totalidades ocidentais definidas epistemologicamente. Ou seja, não é possível pensar o Sul sem o Norte, a colônia sem a metrópole, o escravo sem o amo".

Existe uma busca incessante pelos países e pelas grandes corporações farmacêuticas, químicas e alimentares, no que tange ao controle sistemático dos recursos genéticos do planeta, assim como da água e da energia. De um lado, os países industrializados (Norte), com o aporte da tecnologia e, consequentemente, com a hegemonia mundial, comandam à questão geopolítica do neoliberalismo ambiental, e exploram a diversidade biológica e os conhecimentos tradicionais oriundos dos povos nos países que estão do outro lado (Sul) (NUNES; TYBUSCH, 2013, p. 149). 
Segundo Carlos Walter Porto Gonçalves (2012) é necessário segurança para que as grandes organizações corporativas realizem as pesquisas. Para isso, acrescenta que os Estados Unidos, (país do Norte), com toda sua influência diplomática que exerce para que se aprovem legislações internacionais, como o Acordo TRIPS, favoráveis ao livre acesso dos recursos genéticos, como as leis que garantem barreiras de acesso por meio da propriedade intelectual, garantem essa segurança.

Diante dessa perspectiva, vislumbra-se uma sintonia entre a relação das corporações com o Estado, na qual a estratégia se evidencia na busca de um objetivo comum, a hegemonia. Como analogia pode-se citar a relação estratégica que existiu recentemente com a guerra do Iraque. Nesse episódio houve uma relação entre os Estados Unidos e as grandes corporações do mundo das comunicações contra o governo do Iraque, quando essas empresas da mídia assumiram publicamente uma perspectiva pró-governamental. Aliás, ali também ficara evidente o entrelaçamento dos interesses do Estado com as grandes cadeias do mundo das comunicações (PORTO GONÇALVES, 2012, p. 314-318).

As maiores organizações internacionais beneficiam-se da biodiversidade dos países em desenvolvimento (Sul), muito além da apropriação apenas de seus recursos, como também se utilizam do conhecimento tradicional das comunidades locais, sendo um exemplo disso, a exploração dos conhecimentos milenares das comunidades indígenas. Em consequência, aproveitam-se do material recolhido e do conhecimento obtido para, com a anuência do sistema de patentes e utilizando-se dos padrões tecnológicos alcançados em suas pesquisas, transformarem em novos produtos a serem comercializados nos países de onde retiram a matéria prima, ou seja, dos países em desenvolvimento (do Sul). Dessa forma, resta evidenciado o confronto entre o conhecimento tradicional e o conhecimento científicotecnológico (NUNES; TYBUSCH, 2013, p. 150).

Para que haja uma (des)construção do paradigma hegemônico, e, consequentemente, um fortalecimento dos países em desenvolvimento, com a transferência de tecnologia, proteção da biodiversidade e do conhecimento dos povos tradicionais, necessita-se de um reconhecimento do homem como parte da natureza e não sob a mesma. Segundo a autora Vandana Shiva, os atos do homem, devem pautar-se na proteção à vida das mais variadas espécies e das comunidades diversificadas que convivem com elas.

[...] a biodemocracia implica que os Estados nacionais protejam esses direitos mais antigos da erosão levada a cabo pelas reivindicações à propriedade privada de seres vivos por meio de patentes e direitos de propriedade intelectual defendidas por 
grandes empresas. Quanto maior a devolução e descentralização dos direitos à biodiversidade, tanto menores as chances de as tendências monopolistas assumirem o poder. Para remediar o desequilíbrio Norte-Sul e reconhecer as contribuições das comunidades locais para o desenvolvimento da biodiversidade, é imperativo que o regime baseado no bioimperialismo seja substituído por estruturas baseadas na biodemocracia (SHIVA, 2003, p. 114-117).

Conforme Enrique Leff (2006, p. 287), “a racionalidade ambiental que conduz a construção da sustentabilidade contém um sentido prospectivo em um processo de transformação histórica e mudanças sociais em que teoria se enlaça com a práxis”. A razão dominante como estratégia na construção do saber ambiental é quem pauta o senso crítico da racionalidade ambiental. Com isso, as práticas tradicionais, por meio da razão ambiental, incorporam os valores culturais dos camponeses e da comunidade indígena que, por sua vez, provocam a desconstituição da racionalidade dominante e, na sequência, implica a descolonização e a libertação dos saberes locais.

Por fim, alguns fatores que podem influenciar em uma unificação da legislação normativa do sistema de patentes, passa pela análise do "acesso aos recursos genéticos e aos conhecimentos tradicionais associados, o consentimento prévio fundamentado e a repartição justa e equitativa dos benefícios" (SANTILLI, 2004, p. 355).

\section{CONCLUSÃO}

No presente ensaio analisaram-se com amplitude as questões que envolvem as peculiaridades da biotecnologia e a problemática da propriedade intelectual sobre os recursos genéticos e os conhecimentos dos povos tradicionais. No sistema internacional de patentes revelaram-se conflitos existentes entre as normas da Convenção da Diversidade Biológica (CDB) e o Acordo TRIPS. Atentou-se para um modelo pautado na perspectiva capitalista, com viés na base econômica, no que tange ao reconhecimento de patentes, causando o distanciamento dos países em desenvolvimento (Sul) do avanço às tecnologias e, consequentemente o poder hegemônico dos países desenvolvidos (Norte).

Com o atual sistema internacional de patentes o desrespeito com os direitos e a preservação do meio ambiente e do conhecimento das comunidades locais restam evidenciados. À medida que, corporações privadas, por meio do uso exclusivo da biotecnologia, são detentoras da propriedade intelectual dos recursos naturais retirados dos povos locais, assim como, dos conhecimentos tradicionais. A apropriação dos saberes locais, com a utilização dos conhecimentos para, única e exclusiva, vantagem econômica dos países 
desenvolvidos (Norte), acaba por prejudicar o avanço nos países em desenvolvimento (Sul), e, por conseguinte, nessas comunidades.

Com isso, o modelo hegemônico de dominação dos países do Norte sob os recursos biodiversos e os conhecimentos locais nos países do Sul se faz presente. A questão dos países industrializados, obterem a titularidade da maioria das patentes por licenciamento de tecnologia, e um pequeno investimento em pesquisas e desenvolvimento dos países em desenvolvimento, aumenta mais a discrepância de utilização da tecnologia entre os eixos norte-sul.

Fazem-se necessárias medidas eficazes para uma desconstrução do sistema de patentes vigente, calcado em bases capitalistas. A reformulação com propostas que versem sobre o acesso aos recursos genéticos e aos conhecimentos tradicionais associados, o consentimento prévio fundamentado e a repartição justa e equitativa dos benefícios devem ser dispostas.

A possível solução passa pelo reconhecimento da falência do regime internacional de propriedade intelectual costurado em bases econômicas e a implementação de um modelo contra hegemônico compatível com a proteção da diversidade e a Convenção sobre Diversidade Biológica, deixando a biotecnologia ao alcance dos países em desenvolvimento. Para tanto, implica na necessidade do homem de reconhecer uma multiculturalidade e, a partir desse reconhecimento, haver uma aplicação coerente com a utilização do que é a base em cada cultura.

Também implica discutir a regulamentação de patentes para além do conhecimento científico e tecnológico, reconhecendo o homem como parte da natureza e não apenas detentor dela. Por fim, a unificação da normatização do sistema internacional de propriedade intelectual ou a criação de um regime jurídico sui generis, para que haja proteção aos saberes locais e a biodiversidade com a efetiva, justa e equitativa repartição dos benefícios oriundos da utilização da biotecnologia.

\section{REFERÊNCIAS}

CARVALHO, A. P. Biotecnologia. In. SCHWARTZMAN, S. Ciência e Tecnologia no Brasil: a capacitação brasileira para a pesquisa tecnológica e científica. Rio de Janeiro: Ed. Fundação Getúlio Vargas, 1996. 
CORREA, Carlos M. Propriedade Intelectual e Saúde Pública. Florianópolis: Fundação Boiteux, 2007.

Aperfeiçoando a eficiência econômica e a equidade pela criação de leis de propriedade intelectual. In: VARELLA, Marcelo Dias. Propriedade intelectual e desenvolvimento. São Paulo: Lex Editora, 2005. Cap. II, p. 35-73.

DE GREGORI, Isabel Christine Silva de. Os conhecimentos tradicionais e a biodiversidade: direitos intelectuais coletivos ou monopólio da natureza. In: TYBUSCH, Jerônimo Siqueira (org.) Direitos emergentes na sociedade global: anuário do programa de pós-graduação em direito da UFSM. Ijuí: Ed. Unijuí, 2013. p. 139-172.

FIGUEIREDO, Luciana Harumi Morimoto Figueiredo; PENTEADO, Maria Isabel de Oliveira; MEDEIROS. Patrícia Teles. Patenteamentos em biotecnologia agropecuária: cenário brasileiro. Biotecnologia Ciência e Desenvolvimento, 2006, p. 32-39.

GARCIA, Eloi S. Pesquisa, perigo e progresso. O Globo. Rio de Janeiro, 18 abr. 2003,Seção Opinião, p. 7.

LEFF, Enrique. Racionalidade ambiental: a reapropriação social da natureza. Rio de Janeiro: Civilização Brasileira, 2006.

MAIA FILHO, Romero Gonçalves Maia. Conflito entre as determinações da Convenção sobre a Diversidade Biológica e as regras do Acordo TRIPS. Brasília: Funag, 2010

Disponível em: <unag.gov.br/loja/download/906Conflitos_Entre_a_Convencao_sobre_a_Diversidade_Biologica_e_o_Acordo_TRIPS.pdf> Acesso em: 11 jul. 2016.

MOREIRA, Eliane; WANGHON, Moisés de Oliveira; COSTA, Cíntia Reis; MILEO, Bruno Alberto Paracampo; PEREIRA, Pedro Alexandre Rodrigues; PINHEIRO, Victor Salles. Patentes Biotecnológicas: Um estudo sobre os impactos do desenvolvimento da Biotecnologia no Sistema de Patentes Brasileiro. Cesupa, 2003, p. 1-55. 
NUNES, Denise Silva. TYBUSCH, Jerônimo Siqueira. A problemática da biopirataria: reflexões a partir da geopolítica e dos direitos da sociobiodiversidade. In: REDESG - Revista Direitos Emergentes na Sociedade Global. v. 2, n. 1, 2013, p. 142-162. Disponível em: http://periodicos.ufsm.br/REDESG/article/view/9179\#.V5khJFQrK1t Acesso em: 11 jul. 2016.

OLIVEIRA, Fátima. Bioética: uma face da cidadania. Coleção Polêmica. São Paulo: Editora Moderna, 1997.

PAUGH, J.; LAFRANCE, J. C. The U.S. Biotechnology Industry. U.S. Departament of Commerce Office of Technology Policy, julho de 1997.

PORTO-GONÇALVES, Carlos Walter. A globalização da natureza e a natureza da globalização. 3.ed. Rio de Janeiro: Civilização Brasileira, 2012, p. 314-318.

REIS, Carla. Et al. Biotecnologia para saúde humana: tecnologias, aplicações e inserção na indústria farmacêutica. BNDES Setorial, Rio de Janeiro, p. 359-392, mar. 2009. <https://web.bndes.gov.br/bib/jspui/bitstream/1408/2641/1/BS\%2029_Biotecnologia\%20para \%20sa\%C3\%BAde\%20humana_P.pdf>Acesso em: 11 jul. 2016.

SANTILLI, Juliana. Conhecimentos tradicionais associados à biodiversidade: elementos para a construção de um regime jurídico sui generis de proteção. In: VARELLA, Marcelo Dias. PLATIAU, Ana Flávia Barros. (Orgs.). Diversidade biológica e conhecimentos tradicionais. Belo Horizonte: Del Rey, 2004, p. 341-369.

SANTOS, Boaventura de Sousa; MENESES, Maria Paula (Orgs.). Epistemologias do Sul. São Paulo: Cortez, 2010.

SHIVA, Vandana. Biopirataria: a pilhagem da natureza e do conhecimento. Petrópolis: Vozes, 2001. 
Monoculturas da Mente: Perspectivas da biodiversidade e da biotecnologia. Trad. Dinah Azevedo. São Paulo: Gaia, 2003.

SILVA, Maurício de Castro Govêa da. Biotecnologia, democracia e direito. In: Direito, Estado e Sociedade. v.9 - n.27. jul/dez 2005. p. 173-187.

SILVEIRA, J. M. J; FUTINO, A. M.; OLALDE, A. R. Biotecnologia: corporações, financiamento da inovação e novas formas organizacionais. Revista Economia e Sociedade nº 18. Campinas: IE/UNICAMP, 2002.

TYBUSCH, Jerônimo Siqueira. A sustentabilidade multidimensional como ação reflexiva para uma ecologia política pós-colonial. In: América Latina e Caribe na encruzilhada ambiental: dimensões política, jurídica e estratégica. Org. Fernando Estenssoro, [et. al.]. Ijuí, RS: Unijuí, 2011, p. 299.

VIEIRA, Vinícius Garcia. Direito da biodiversidade e América Latina: a questão da propriedade intelectual. Ijuí: Editora Unijuí, 2012. 